\title{
Turbulence study in the vicinity of piano key weir: relevance, instrumentation, parameters and methods
}

\author{
Harinarayan Tiwari • Nayan Sharma
}

Received: 13 October 2014/ Accepted: 19 February 2015/Published online: 11 March 2015

(C) The Author(s) 2015. This article is published with open access at Springerlink.com

\begin{abstract}
This research paper focuses on the need of turbulence, instruments reliable to capture turbulence, different turbulence parameters and some advance methodology which can decompose various turbulence structures at different levels near hydraulic structures. Small-scale turbulence research has valid prospects in open channel flow. The relevance of the study is amplified as we introduce any hydraulic structure in the channel which disturbs the natural flow and creates discontinuity. To recover this discontinuity, the piano key weir (PKW) might be used with sloped keys. Constraints of empirical results in the vicinity of PKW necessitate extensive laboratory experiments with fair and reliable instrumentation techniques. Acoustic Doppler velocimeter was established to be best suited within range of some limitations using principal component analysis. Wavelet analysis is proposed to decompose the underlying turbulence structure in a better way.
\end{abstract}

Keywords Piano key weir - Turbulence - Acoustic Doppler velocimeter - Principal component analysis . Wavelet analysis

\section{Introduction}

Some foremost points of concern in river management near hydraulic structures are transport, spreading and mixing of

H. Tiwari $(\bowtie) \cdot$ N. Sharma

Department of Water Resources Development and Management, Indian Institute of Technology Roorkee, Roorkee, India

e-mail: haribit31@gmail.com

N. Sharma

e-mail: nayanfwt@gmail.com suspended matter and pollutants, transport of sediment and the associated erosion and deposition phenomena. All of these points depend on the turbulence characteristics and transport of turbulent kinetic energy (TKE) by means of turbulent velocity fluctuations in the flow (Blanckaert and De Vriend 2005a, b; Lee et al. 2012; Lien and D'Asaro 2006; Liu et al. 2004; Shvidchenko and Pender 2001). In spite of this practical relevance, a lot of ground is to be covered on turbulence characteristics in open channel and near hydraulic structures. The turbulence closure problem at the current stage still requires experimental data for the development of advanced equations for defining the relations between the fluctuating and the mean velocity fields. Measurements of the mean flow field and the fluctuating velocity correlations including the Reynolds' stresses and the higher-order terms are required for each flow field separately (Byun et al. 2004). The presence of hydraulic structures induces highly anisotropic and physically complex flows in turbulent coherent structures (Blanckaert and De Vriend 2005a, b; Lee et al. 2012).

\section{Piano key weir (PKW)}

A piano key weir is a kind of labyrinth hydraulic structure, in general, placed transversely to rivers that causes flow discontinuity and affects the hydraulics of rivers (Erpicum et al. 2011; Laugier et al. 2012; Ouamane 2013). General transverse structures like weir (triangular or rectangular) have a significant function in maintaining the upstream depth of water and securing water resources for optimum use (Kabiri-Samani and Javaheri 2012; Nayan Sharma 2007; Nayan Sharma 2013; Payne et al. 2004). However, it destabilizes sediment continuity, because flow velocity is reduced due to the increased water depth (Bai and Duan 
2014; Fan and Morris 1992). Due to the restricting nature of sediment downstream, it is deposited directly upstream of a weir (Kim et al. 2014; Kondolf et al. 2014). As sediment from upstream normally moves downstream with flowing water, the geographical features are changed and hydro-ecological habitats are subsequently affected. Inhibited sediment continuity has an effect on the hydroenvironmental status downstream of a weir, which can result in serious disturbance to the riparian ecosystem (Kim et al. 2014). To support the recovery of sediment continuity in rivers, the piano key weir might be used as an alternative transverse structure. It needs the elemental study microturbulence phenomenon near PKW to point out the sediment transport (Sharma et al. 2012). The interaction of flow and sediment transport in rivers creates a variety of interesting phenomena and morphologies, including dunes, bars, meandering, alluvial fans, submarine channels, etc. Insertion of any structure to the flow can change the interaction between flow and sediment transport (Mazumder and Sarkar 2014). For the sediment transport and their interaction study, a comprehensive study of turbulence behavior is required.

\section{Instrumentation techniques and feasibility}

Hydraulic structures which are measurably affected by fluid flow encounter or produce turbulent flow fields (Corino and Brodkey 1969; Gad-el-Hak 1989; Guellouz and Tavoularis 2000). These flow fields are characterized by a chaotic and time-dependent fluid motion that has a wide range of characteristic space and timescales (Simpson 1996, 2001). The existence of many scales of chaotic motion makes turbulent flow phenomena very complex and difficult to predict, even for the most basic situations. The protrusion of a structure constructed in a riverbed or on the lateral bank in the main channel of a river reduces the width of the water course and disturbs the flow and sediment transport (Chen et al. 2011, 2012). The flow at the upstream face of a structure is accelerated as it moves past the obstacle, creating a trailing vortex over the structure and wake vortices near the bed at the downstream face (Dey et al. 2008; Lim 1997; Liu and Shen 2008). The presence of a solid structure strongly induces 3-D flow (Chen et al. 2011, 2012). Radical research of turbulence behavior requires a 3-D velocity measuring instrument with the requisite spatial and temporal resolution. Laboratory investigation of turbulent characteristics of open channel flow was completed with the assistance of several instrumentation techniques. Some of these instrumentation techniques with their advantages and disadvantages are summarized in the following.

\section{Pitot tube}

The theory of flow measurement by Pitot tube was adopted first by a French Scientist Henri Pitot in 1732 A.D. for measuring velocities in the river. The Pitot tube is used to measure the local velocity at a given point in the flow stream. It is a very simple and low-cost device used to measure mean velocities for various industrial purposes (Bryant et al. 2014; Graham et al. 2013; Oh and Lee 2011). The Pitot tube is not suitable for velocities lower than $5 \mathrm{~m} / \mathrm{s}$ (Nakra and Chaudhry 2004) because of low pressure differential availability. The Pitot tube has many disadvantages, as ports for pressure measurements require modification to the wall and present potential disturbance to the flow (Liu et al. 1999). The order of error in the measurement of velocity is up to $20 \%$ as reported by Bakke (1957) and the average error is $\pm 2 \%$ (Nakra and Chaudhry 2004). Pitot tube is not so practicable for turbulence study.

Hot-wire anemometer/hot-film anemometer (HWA/HFA)

These are well-known thermal anemometers and measure a fluid velocity by noting the heat convected away by the fluid. The core of the anemometer is an exposed hot wire/film either heated up by a constant current or maintained at a constant temperature. In either case, the heat lost to fluid convection is a function of the fluid velocity. The average cost of this instrument is in the range of 10,000-20,000 rupees and marked as low-cost velocity-measuring instrument compared to acoustic Doppler velocimeter (around 10-20 lakhs), particle image velocimeter (30-50 lakhs) and laser Doppler velocimeter (1-1.5 crore rupees). HWA/HFA has high spatial resolution (Hutchins et al. 2009) and high frequency response $>10 \mathrm{kHz}$ (up to $400 \mathrm{kHz}$ ). HWA/ HFA has turned into a standard instrument for turbulent research in low-speed flow (Kovasznay 2012). Time constant of the instrument is in the order of $10^{-4}$ $10^{-6} \mathrm{~s}$, which shows its good dynamic characteristics. For the measurement of velocities, the chance of error is $\pm 0.1 \%$ and for turbulence $\pm 2 \%$ (Nakra and Chaudhry 2004). It was demonstrated that hot wire anemometer is intrinsically inappropriate for measuring turbulent temperature correlations; the major reason is the non-linearity of the temperature sensitivity at low overheat ratios. The instrument is therefore restricted to measurements of the mass flow fluctuations (Smits et al. 1983). HWA/HFA requires to be recalibrated frequently due to dust accumulation, so it is used only for very clean environments. 
Acoustic Doppler velocimeter (ADV)

ADV is a single-point, high spatial and temporal resolution 3-D Doppler current meter based on pulse to pulse coherence. ADV has been recommended as a capable instrument for characterizing near-bed flows, particularly in the first $10 \mathrm{~mm}$ above the bed (Finelli et al. 1999) with suitable assumptions. It has been widely used across the world for laboratory (Duan et al. 2011; Nikora and Goring 1998; Song and Chiew 2001; Voulgaris and Trowbridge 1998; Wang et al. 2012) as well as field turbulence measurements (Chanson et al. 2005; Chanson et al. 2008; García et al. 2007; Sukhodolov et al. 1998). ADV was advised for turbulence measurement, because of the random noise is about $1 \%$ and the low sampling volume $0.09 \mathrm{cc}$ is undisturbed by the presence of the probe (Sukhodolov et al. 1998; Voulgaris and Trowbridge 1998). Velocity resolution of $\mathrm{ADV}$ is $0.1 \mathrm{~mm} / \mathrm{s}$ and range is \pm 0.03 to $\pm 2.5 \mathrm{~m} / \mathrm{s}$ (Nikora and Goring 1998). Its cost ranges from 7 to 15 lakh rupees for different specifications. Agreement of mean velocities within $\pm 1 \%$ than LDA and $1 \%$ underestimation of Reynolds stresses make ADV a quite frequently used instrument (Voulgaris and Trowbridge 1998).

Particle image velocimetry (PIV)

It is a non-intrusive instrumentation system with no alteration of the fluid flow characteristics at the scale of interest. PIV can observe instantaneous velocity vector maps in a cross section of the flow. The uncorrected PIV measurements of the TKE are significantly underestimated due to poor spatial resolution (Lavoie et al. 2007).

\section{Laser Doppler velocimeter (LDV)}

LDV is a device which is used for measuring the velocities of moving test specimens employing a laser beam source. It is a well-established flow measurement technique that is capable of providing high-quality, high spatial resolution data over a range of flow conditions (Penney 1969; Stein and Pfeifer 1969; Yeh and Cummins 1964). It is the noncontact type instrument with $\pm 0.2 \%$ of mean velocity error and low sample volume of $0.008 \mathrm{~mm}^{3}$. This system relies upon the measurement of the Doppler frequency shift of light scattered from an illuminating laser beam by particles entrained within the flow. It has also been widely used for open channel laboratory turbulence measurements (Ali et al. 2013; Buchhave et al. 1979; Nakagawa and Nezu 1987; Nezu and Rodi 1986; Nezu and Sanjou 2011; Tachie et al. 2000; Tominaga and Nezu 1991), but it is infrequently used under field conditions because of its size. Deterioration of optical transmissions due to turbidity and higher cost also make its use lesser (Agrawal and Aubrey 1992; Agrawal and Belting 1988).

\section{Instrument reliability using principal component analysis (PCA)}

Principal component analysis (PCA) is probably the oldest and frequently applied techniques of multivariate analysis (Abdi and Williams 2010). The fundamental idea of PCA is to reduce the dimensionality of a data set consisting of multiple variables, while retaining as much as possible the existing variation in the data set. PCA is a data testing tool that generally condenses the dimensionality of a large number of interconnected variables (Grahn et al. 1989; Mujica et al. 2008; Wang and Cui 2005). It may be referred to as a data analytical, rather than a statistical tool. This is achieved by transforming to a new set of variables the principal components (PCs), which are uncorrelated and which are ordered, so that the first few retain most of the variation present in all of the original variables.

The above described all five velocity-measuring instruments were analyzed based on their ranking taken from literature and verified by experts. Ranking of various instruments was elaborated within their range of characteristics in Table 1. The PCA method was used to find the reliability of available instruments within their range of characteristics. The PCA was done on the correlation matrix. The correlation matrix (Table 2) was preferred because it was desired to treat all variables on an equal footing.

Table 3 gives the coefficients and variances for the first four PCs using the correlation matrix for the above-mentioned data sets. It is seen from Table 3 that the first two components account for $81.9 \%$ of the total variation and from scree plot (Fig. 1) it has also been seen that two PCs have eigenvalue greater than 1 . There are reasonably clear

Table 1 Ranking of instruments

\begin{tabular}{llllll}
\hline Property/instruments & $\mathrm{PT}^{\mathrm{a}}$ & $\mathrm{HWA}^{\mathrm{b}}$ & $\mathrm{ADV}^{\mathrm{c}}$ & $\mathrm{PIV}^{\mathrm{d}}$ & $\mathrm{LDV}^{\mathrm{e}}$ \\
\hline Cost & 1 & 2 & 3 & 4 & 5 \\
Time & 5 & 4 & 2 & 3 & 1 \\
Accuracy in clear water & 5 & 2 & 3 & 4 & 1 \\
Accuracy in turbid water & 4 & 5 & 1 & 2 & 3 \\
Calibration & 3 & 5 & 1 & 4 & 2 \\
Disturbance to flow & 5 & 4 & 3 & 2 & 1 \\
Turbulence and Reynolds stress & 5 & 4 & 2 & 3 & 1 \\
Handling & 3 & 1 & 2 & 4 & 5 \\
Skilled Worker Requirement & 1 & 2 & 3 & 4 & 5 \\
Remote Field Application & 3 & 1 & 2 & 4 & 5 \\
\hline
\end{tabular}

\footnotetext{
${ }^{a}$ Pitot tube

b Hot wire anemometer

c Acoustic Doppler velocimeter

${ }^{d}$ Particle image velocimeter

e Laser Doppler velocimeter
} 
Table 2 Correlations and standard deviations for instruments

\begin{tabular}{lccccc}
\hline & $\mathrm{PT}^{\mathrm{a}}$ & $\mathrm{HWA}^{\mathrm{b}}$ & $\mathrm{ADV}^{\mathrm{c}}$ & $\mathrm{PIV}^{\mathrm{d}}$ & $\mathrm{LDV}^{\mathrm{e}}$ \\
\hline PT $^{\mathrm{a}}$ & 1 & 0.449 & -0.178 & -0.583 & -0.864 \\
HWA $^{\mathrm{b}}$ & 0.449 & 1 & -0.541 & -0.674 & -0.669 \\
ADV $^{\mathrm{c}}$ & -0.178 & -0.541 & 1 & 0.200 & 0.088 \\
PIV $^{\mathrm{d}}$ & -0.583 & -0.674 & 0.200 & 1 & 0.510 \\
LDV $^{\mathrm{e}}$ & -0.864 & -0.669 & 0.088 & 0.510 & 1 \\
STDEV & 1.5 & 1.48 & 0.75 & 0.8 & 1.81
\end{tabular}

${ }^{a}$ Pitot tube

${ }^{\mathrm{b}}$ Hot wire anemometer

c Acoustic Doppler velocimeter

${ }^{\mathrm{d}}$ Particle image velocimeter

e Laser Doppler velocimeter

Table 3 Principal components based on the correlation matrix five instruments

\begin{tabular}{lcccc}
\hline \multirow{2}{*}{$\begin{array}{l}\text { Components number } \\
\text { Instruments }\end{array}$} & \multicolumn{4}{l}{ Coefficients } \\
\cline { 2 - 5 } & 1 & 2 & 3 & \multicolumn{2}{l}{} \\
\hline PT $^{\mathrm{a}}$ & -0.5216 & -0.4506 & 0.5696 & 0.0208 \\
$\mathrm{HWA}^{\mathrm{b}}$ & -0.4561 & 0.748 & -0.1755 & -0.0416 \\
$\mathrm{ADV}^{\mathrm{c}}$ & 0.0814 & -0.3807 & -0.5565 & -0.5821 \\
$\mathrm{PIV}^{\mathrm{d}}$ & 0.2118 & -0.1694 & -0.32 & 0.79 \\
$\mathrm{LDV}^{\mathrm{e}}$ & 0.6844 & 0.2527 & 0.4824 & -0.1871 \\
\% Variance & 60.1 & 21.8 & 11.1 & 6.9 \\
\hline
\end{tabular}

${ }^{\text {a }}$ Pitot tube

${ }^{b}$ Hot wire anemometer

c Acoustic Doppler velocimeter

d Particle image velocimeter

${ }^{\text {e }}$ Laser Doppler velocimeter

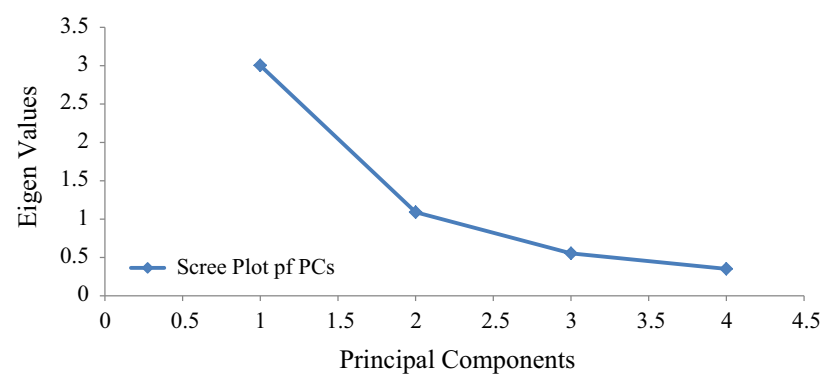

Fig. 1 Scree plot of principal components (instrument reliability analysis)

interpretations for each of the first two PCs. The first PC provides a contrast between costly and cheaper instruments, with positive coefficients for variables that are high in cost. The main contrast for component 2 is between the calibration and accuracy in sediment-laden water. This component is therefore a measure of the technical and
Table 4 Extracted communalities and component matrix for instruments

\begin{tabular}{llllrr}
\hline Instruments & \multicolumn{2}{l}{ Communalities } & & \multicolumn{2}{c}{ Component } \\
\cline { 2 - 3 } \cline { 6 - 7 } & Initial & Extraction & & 1 & \multicolumn{1}{c}{2} \\
\hline PT $^{\mathrm{a}}$ & 1 & 0.83 & & -0.836 & 0.362 \\
$\mathrm{HWA}^{\mathrm{b}}$ & 1 & 0.848 & & -0.859 & -0.332 \\
$\mathrm{ADV}^{\mathrm{c}}$ & 1 & $\mathbf{0 . 8 9 6}$ & & 0.424 & $\mathbf{0 . 8 4 6}$ \\
$\mathrm{PIV}^{\mathrm{d}}$ & 1 & 0.634 & & 0.796 & -0.033 \\
$\mathrm{LDV}^{\mathrm{e}}$ & 1 & 0.886 & & 0.868 & -0.363 \\
\hline
\end{tabular}

${ }^{\text {a }}$ Pitot tube

b Hot wire anemometer

c Acoustic Doppler velocimeter

d Particle image velocimeter

e Laser Doppler velocimeter

management feasibility (in terms of handling) for instruments.

A scree plot is displayed in Fig. 1, in which the eigenvalues associated with a component or factor are given in descending order versus the number of the components or factors. Projection of the variables on the factor plane revealed that the first and the second axes of the PCs explained 60.1 and $21.8 \%$ of the total variance.

Extraction communalities are estimates of the variance in each variable accounted for by the two components. High communalities indicate that the extracted components represent the variables well. If any communality is very low in a principal component extraction, you may need to extract another component. Dimension reduction (PCA) using SPSS $^{22}$ shows that ADV is most reliable with maximum communalities of 0.896 and PIV has the lowest, 0.634 (Table 4). This analysis may vary with different characteristics.

\section{Parameters and methods}

The turbulence near a hydraulic structure has been the subject of theoretical and experimental research for the past few decades due to sediment transport (Hino et al. 1983; Nagata et al. 2005; Raupach et al. 1991; Raupach and Thom 1981; Speziale 1990). Sediment transport is highly intermittent and it was hypothesized that this was due to an intermittence of the turbulent intensities caused by coherent structures of the turbulent flow field (Grass 1971; Raupach et al. 1996; Rhoads and Massey 2012). It is common to analyze these coherent structures by using the quadrant method (Nezu 2005). Reynolds stress was partitioned into four events: ejection, sweep, inward interaction, and outward interaction events (Nakagawa and Nezu 1977, 1981; Nezu 1993). Events in the second quadrant $\left(\mathrm{u}^{\prime}<0\right.$, 
$\left.\mathrm{w}^{\prime}>0\right)$ are called ejections and in the fourth $\left(\mathrm{u}^{\prime}>0\right.$, $\mathrm{w}^{\prime}<0$ ), sweeps (Nakagawa and Nezu 1981). The ejection events can be recognized with a signature of negative fluctuation components in stream-wise velocity $\left(\mathrm{u}^{\prime}<0\right)$ as well as positive fluctuation components in wall-normal velocity $\left(\mathrm{w}^{\prime}>0\right)$. Sweep in high-speed fluid rushes in from the outer region toward the wall at a small angle of incidence. The sweep events can be recognized with a signature of positive fluctuation components in stream-wise velocity $\left(\mathrm{u}^{\prime}>0\right)$ as well as negative fluctuation components in wall-normal velocity $\left(\mathrm{w}^{\prime}<0\right)$.

Conditional function (Duan et al. 2011) and Reynolds stresses (Nakagawa and Nezu 1977; Raupach 1981; Raupach et al. 1996) are some of the most important parameters that can quantify turbulence around the hydraulic structure. Both of these parameters are of second order only. Third-order parameters like TKE flux in stream-wise and vertical direction were discussed in literatures (Bey et al. 2007; Dey et al. 2011; Krogstadt and Antonia 1999; Wang et al. 2012). Turbulent diffusion, a third-order parameter, was also mentioned in several turbulence researches (da Silva et al. 2014; Elder 1959; Jones and Whitelaw 1982; McComb 1990; Reeks 2014; Taylor 1954). Higher-order velocity structures such as 4th-order (Hoyas and Jiménez 2006) and up to 18 order (Anselmet et al. 1984) were also available in previous studies.

In the age of fast computation techniques, higher-order velocity fluctuations were analyzed using Fourier transformation (Salazar and Collins 2012), but it was also rated as an ill performer for signature characteristics of time series in hydraulic engineering spectrum (Gurley et al. 2003). Wavelet analysis is often used to learn evolutionary behavior with relatively short duration data to characterize fluctuated velocity time series (Gurley and Kareem 1999; Gurley et al. 2003; Kumar and Foufoula-Georgiou 1997). The basic dissimilarity between wavelet and Fourier analysis is that the wavelet basis function can distinguish local events at different times at the same frequency. In the Fourier basis functions, momentary events are blended into one coefficient (Gurley and Kareem 1999).

\section{Piano key weir and turbulence}

The piano key weir is a hydraulic engineering structure for preserving the desired water depth, free flow spillways in rivers, and protecting dam failure under unforeseen flood conditions. Protrusion of the piano key weir to a channel leads to considerable changes of flow patterns (Nayan Sharma 2013) and bed configurations. These changes convey us either negative view mainly in terms of siltation or positive view such as enhancement of morphological diversities. The piano key weir technology has enhanced discharge capacity due to increased crest length and it can be investigated for the sediment transport via turbulence characteristics. Study of sediment transport is very significant for mountainous river as it consists of high sediment discharge. Considerable increasing vertical turbulence characteristics on approaching the structure is a signature of less sediment retention in the upstream (Nayan Sharma 2013; Sharma et al. 2012; Tiwari and Sharma 2014). This can make PKW a better dam rehabilitation hydraulic structure. It will assure less upstream submergence and promote PKW as a socially acceptable technology for in-stream storage as well as a diversion structure.

The PKW has a rectangular nonlinear weir crest layout (in planform); unlike traditional labyrinth weirs, the sloped floor in the inlet and outlet cycles, referred to as keys, overhangs the apexes providing a longer crest length than a rectangular labyrinth weir, and several times the transverse weir width. The piano key weir does not have any gates. So it will involve very little operation and maintenance and would be very much cheaper than conventional dam spillways or barrage structure. Mountainous rivers of India transport higher sediment concentration through it \& because of this the use of PKW may be promoted by answering the question of sedimentation mechanism behind it. As sediment from upstream normally moves downstream along with flowing water, the geographical features are changed and hydro-ecological habitats are subsequently affected. Inhibited sediment continuity has an effect on the hydro-environmental status downstream of a weir, which can result in serious disturbance to the riparian ecosystem. To support recovery of sediment continuity in rivers, the piano key weir might be used as an alternative transverse structure. It needs the elemental sediment transport study in the approach flow PKW to point out the physical hydraulic characteristics. Research found that the turbulence structure played a significant role in sediment transport and suspension (Duan et al. 2009, 2011). The measured turbulent flow field (e.g., turbulence intensities, Reynolds shear stresses, turbulence diffusion, conditional functions and flow structures) at various levels in the upstream of the flow is needed for accurate estimation of sediment transport. These turbulent parameters in the upstream of a piano key weir can be investigated experimentally. For these researches, at first we have to clearly understand the terminology behind it.

\section{Time series}

The primary data supplied by an ADV is a time series of velocity vector components (Fig. 2). The sample reporting 
Fig. 2 Measured time series and its disintegration $(16 \mathrm{MHz}$, $25 \mathrm{~Hz}$ )
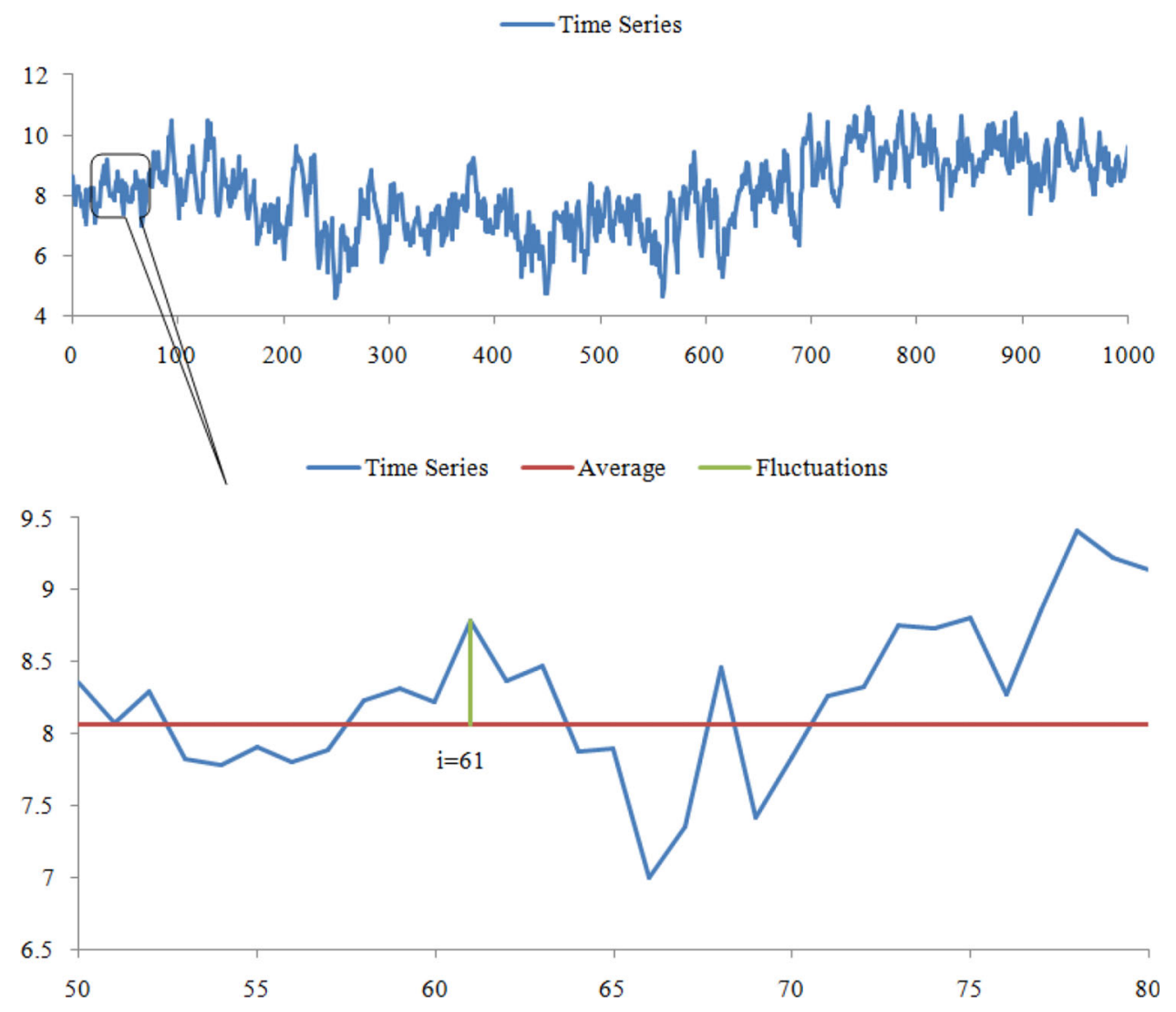

rate can be varied from 0.1 to $200 \mathrm{~Hz}$ on the instruments that operate at an acoustic frequency of $10,16 \mathrm{MHz}$, etc.

Mean velocity, turbulent fluctuation and turbulence intensity (TI)

As illustrated in Fig. 1, measured time series can be disintegrated into average and fluctuated part. Mathematical$1 y$, it is expressed as given in Eqs. 1-4. The average of the square of the turbulent part of a velocity can be understood as the variance of velocity, i.e., turbulence intensity. Reynolds disintegration into average and fluctuating portions is in use commonly for analyzing the turbulence velocity field. Fine sand, silt, and clay are transported as suspended sediment in a water column and settle where the turbulence intensity is weak (Duan et al. 2009, 2011).

$\bar{u}=\frac{1}{N} \sum_{i=1}^{i=n} u_{i}$,

$\bar{u}_{i}=u_{i}-\bar{u}$,

$u_{\mathrm{rms}}=\sqrt{\frac{1}{N} \sum_{1}^{N}\left(u_{i}^{\prime}\right)^{2}}$,
$\mathrm{TI}=\frac{u_{\mathrm{rms}}}{\bar{u}}$.

Normal stress

The dimensionless normal stress is the ratio of turbulence intensity to the friction velocity (Eqs. 5-7). Longitudinal and lateral normal stresses are the signature of sediment transport and vertical normal stress can be attributed for sediment in suspension (da Silva et al. 2014):

Normalized longitudinal normal stress

$$
=\overline{\left[\left\{\sum_{i=1}^{i=n} u_{i}^{\prime 2}\right\} / u_{*}^{2}\right]}
$$

Normalized lateral normal stress $=\overline{\left[\left\{\sum_{i=1}^{i=n} v_{i}^{\prime 2}\right\} / u_{*}^{2}\right]}$

Normalized vertical normal stress $=\overline{\left[\left\{\sum_{i=1}^{i=n} w_{i}^{\prime 2}\right\} / u_{*}^{2}\right]}$. 
Fig. 3 Schematic diagram of secondary current

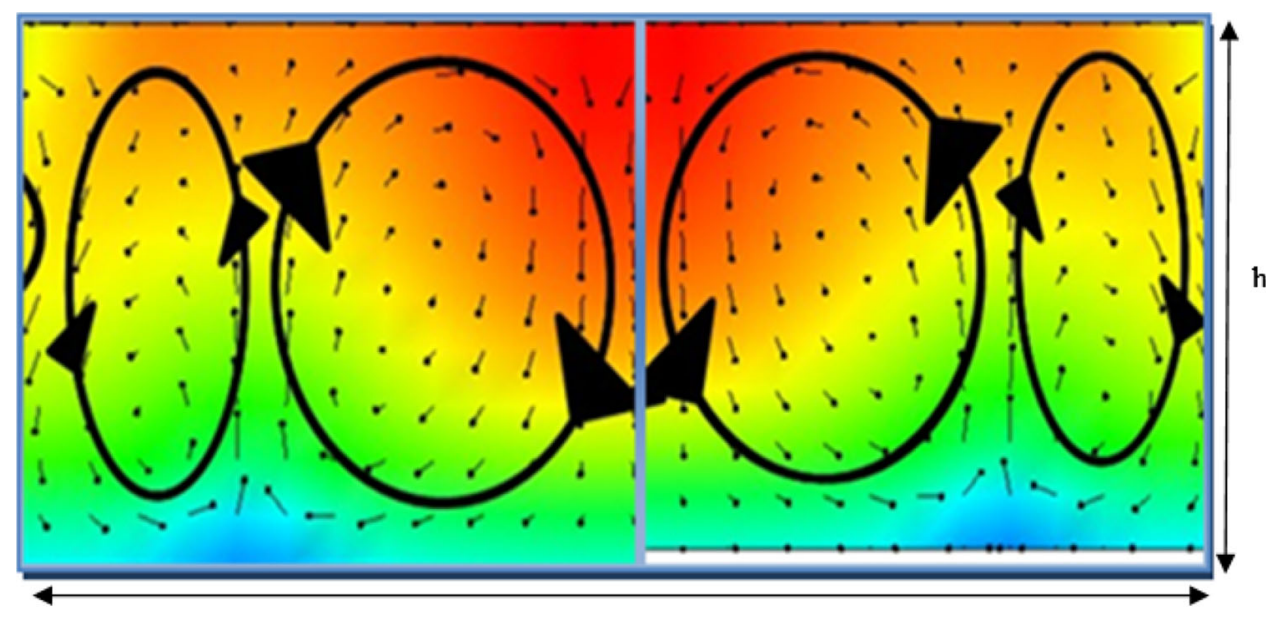

B
Reynolds stress

The dimensionless Reynolds stress is the ratio of transverse gradient to the friction velocity (Eqs. 8-10). It is mainly responsible for secondary current generation and also contributes to mixing as well as sediment transportation (Nakagawa and Nezu 1977; Raupach 1981; Speziale 1990):

Normalized reynolds stress $=\overline{\left[\left\{\sum_{i=1}^{i=n} u_{i}^{\prime} v_{i}^{\prime}\right\} / u_{*}^{2}\right]}$,

Normalized reynolds stress $=\overline{\left[\left\{\sum_{i=1}^{i=n} v_{i}^{\prime} w_{i}^{\prime}\right\} / u_{*}^{2}\right]}$,

Normalized reynolds stress $=\overline{\left[\left\{\sum_{i=1}^{i=n} w_{i}^{\prime} u_{i}^{\prime}\right\} / u_{*}^{2}\right]}$.

Turbulent kinetic energy (TKE)

In open channel flow, TKE is the mean kinetic energy per unit mass linked with eddies in turbulent flow. Physically, the TKE is characterized by calculated root-mean-square (RMS) velocity fluctuations (Ali et al. 2013; Lien and D'Asaro 2006). In general, the TKE can be quantified (Eq. 11) by the mean of the turbulence normal stresses (Eqs. 5-7). TKE can be produced by friction, fluid shear or through external forcing at low-frequency eddy scales (integral scale). Turbulence kinetic energy is then shifted down the turbulence energy cascade and dissipated by viscous forces at the Kolmogorov scale (Poggi et al. 2003):

$k=\frac{1}{2}\left\langle u_{i} u_{i}\right\rangle=\sum_{i=1}^{i=n} \frac{1}{2}\left(\overline{u_{i}^{\prime 2}}+\overline{v_{i}^{\prime 2}}+\overline{w_{i}^{\prime 2}}\right)$.

Secondary currents

There are two types of secondary currents identified in fluid flow. First is the mean flow-originated secondary currents which are driven by the curvature effect (also termed as skew-induced stream-wise vortices). Secondary currents of the second kind (also known as corner-induced secondary currents), as observed in straight and non-circular channels, are generated by turbulence (Duan et al. 2009). There is evidence that secondary currents are both the reason as well as the consequences of the sediment deposit patterns and the geomorphologic patterns. The schematic diagram (Fig. 3) presents a rectangular open channel with secondary current generation, where " $\mathrm{B}$ " represents width and "h" flow depth. It can be formulated as Eqs. 12 and 13:

$\mathrm{SC}=\overline{\left[\sum_{i=1}^{i=n} v_{i}^{\prime 2}-w_{i}^{\prime 2} / u_{*}^{2}\right]}$

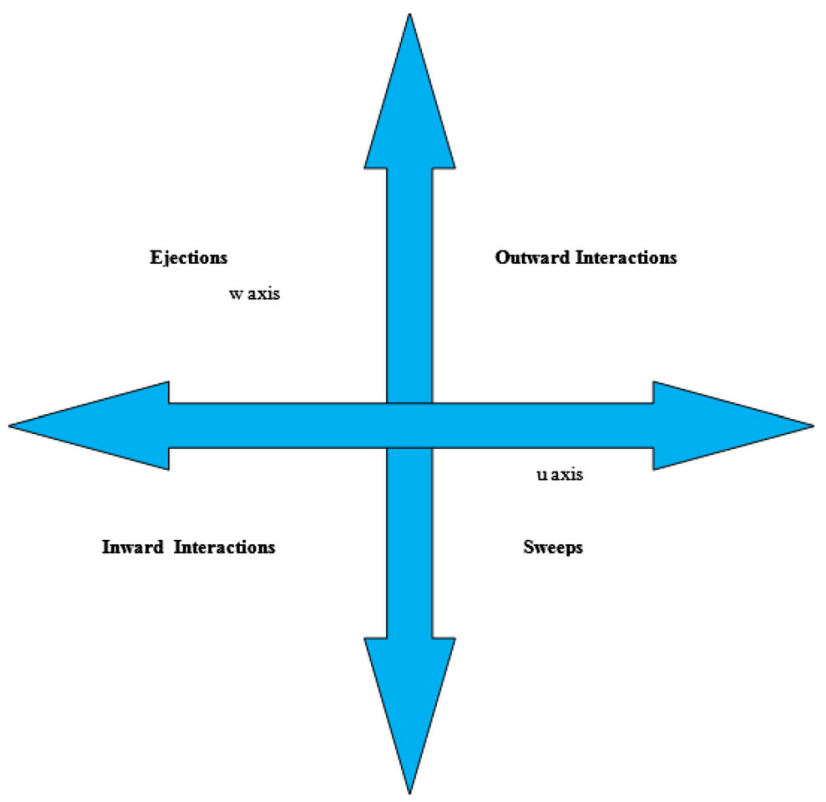

Fig. 4 Quadrant events of velocity 
$\mathrm{SC}=\overline{\left[\sum_{i=1}^{i=n} \sqrt{v_{i}^{\prime 2}+w_{i}^{\prime 2}} / u_{*}\right] .}$

Quadrant events

Flow structures generated in fluid flow affect the sediment distribution in vertical plane and the resistance to flow (Bennett et al. 2014; Bennett and Best 1995). These structures can be analyzed (Eq. 14) using the quadrant method (Bennett and Best 1995; Keylock et al. 2014; Kim et al. 1987; Nakagawa and Nezu 1977; Nezu 1993; Roy et al. 2004; Tominaga and Nezu 1991):

$\% Q_{i}=\frac{\text { Events in } i^{\text {th }} \text { quadrant }(i=1,2,3,4)}{\text { Total number of events in all quadrants }} \times 100$.

In this method, the Reynolds stresses were partitioned into four events: ejection, sweep, inward interaction, and outward interaction events (Adrian and Marusic 2012; Nezu 2005) (Fig. 4).

\section{Conclusions}

The piano key weir technology has enhanced discharge capacity due to increased crest length and should be investigated for local sediment behavior. Sediment transport in open channel is directly linked with turbulence structures. Physics, especially about turbulence phenomena (with the help of quadrant event study), will be helpful to decide the design criteria of PKW. Turbulence is a very complex phenomenon in an open channel included with PKW and needs extensive laboratory experiment. ADV is exceedingly reliable to capture turbulence characteristics in open channel flow in laboratory as well as in field. Higherorder velocity structure can be captured using ADV. Up to third-order parameters and turbulence phenomenon have been described in previous studies on open channel. These obtained experimental velocity data can be described under certain defined parameters such as quadrant events, Reynolds stresses, flux and diffusion. Statistics of these parameters will extract important information for empirical derivations in local PKW sediment transport as well as closure of numerical modeling of PKW. Higher-order turbulent structures using wavelet analysis are able to capture local events, which will be helpful for turbulence research in the vicinity of PKW.

Acknowledgments The authors are grateful to the Department of Water Resources Development and Management, Indian Institute of Technology, Roorkee, India. They are also thankful to the Ministry of Human Resource Development: Government of India, for their regular fellowship to conduct research.
Open Access This article is distributed under the terms of the Creative Commons Attribution License which permits any use, distribution, and reproduction in any medium, provided the original author(s) and the source are credited.

\section{References}

Abdi H, Williams LJ (2010) Principal component analysis. Wiley Interdiscip Rev: Comput Stat 2(4):433-459

Adrian RJ, Marusic I (2012) Coherent structures in flow over hydraulic engineering surfaces. J Hydraul Res 50(5):451-464

Agrawal Y, Aubrey D (1992) Velocity observations above a rippled bed using laser Doppler velocimetry. J Geophys Res Oceans (1978-2012) 97(C12):20249-20259

Agrawal Y, Belting C (1988) Laser velocimetry for benthic sediment transport. Deep Sea Res Part A Oceanogr Res Papers 35(6):1047-1068

Ali S, Ghani U, Latif A (2013) Study of turbulent kinetic energy and reattachment length downstream the obstruction in an open channel. Life Sci J 10(10s)

Anselmet F, Gagne Y, Hopfinger E, Antonia R (1984) High-order velocity structure functions in turbulent shear flows. J Fluid Mech 140(63):63-89

Bai Y, Duan JG (2014) Simulating unsteady flow and sediment transport in vegetated channel network. J Hydrol 515:90-102

Bakke P (1957) An experimental investigation of a wall jet. J Fluid Mech 2(05):467-472

Bennett S, Best J (1995) Mean flow and turbulence structure over fixed, two-dimensional dunes: implications for sediment transport and bedform stability. Sedimentology 42(3):491-513

Bennett G, Molnar P, McArdell B, Burlando P (2014) A probabilistic sediment cascade model of sediment transfer in the Illgraben. Water Resour Res 50(2):1225-1244

Bey A, Faruque M, Balachandar R (2007) Two-dimensional scour hole problem: role of fluid structures. J Hydraul Eng 133(4):414-430

Blanckaert K, De Vriend H (2005a) Turbulence characteristics in sharp open-channel bends. Phys Fluids 17:055102

Blanckaert K, De Vriend H (2005b) Turbulence structure in sharp open-channel bends. J Fluid Mech 536:27-48

Bryant R, Sanni O, Moore E, Bundy M, Johnson A (2014) An uncertainty analysis of mean flow velocity measurements used to quantify emissions from stationary sources. J Air Waste Manag Assoc 64(6):679-689

Buchhave P, George WK Jr, Lumley JL (1979) The measurement of turbulence with the laser-Doppler anemometer. Ann Rev Fluid Mech 11(1):443-503

Byun G, Ölçmen SM, Simpson RL (2004) A miniature laser-Doppler velocimeter for simultaneous three-velocity-component measurements. Meas Sci Technol 15(10):2075

Chanson H, Trevethan M, Aoki SI (2005) Acoustic Doppler Velocimetry (ADV) in a Small Estuarine System. Field Experience and Despiking. In: Proc., XXXI IAHR Biennial Congress. pp 880-882

Chanson H, Trevethan M, Aoki S-I (2008) Acoustic Doppler velocimetry $(A D V)$ in small estuary: field experience and signal post-processing. Flow Meas Instrum 19(5):307-313

Chen S-C, Kuo Y-M, Li Y-H (2011) Flow characteristics within different configurations of submerged flexible vegetation. J Hydrol 398(1):124-134

Chen S-C, Kuo Y-M, Yen H-C (2012) Effects of submerged flexible vegetation and solid structure bars on channel bed scour. Int $\mathrm{J}$ Sedim Res 27(3):323-336 
Corino ER, Brodkey RS (1969) A visual investigation of the wall region in turbulent flow. J Fluid Mech 37(01):1-30

da Silva CB, Hunt JC, Eames I, Westerweel J (2014) Interfacial layers between regions of different turbulence intensity. Ann Rev Fluid Mech 46:567-590

Dey S, Raikar RV, Roy A (2008) Scour at submerged cylindrical obstacles under steady flow. J Hydraul Eng 134(1):105-109

Dey S, Sarkar S, Solari L (2011) Near-bed turbulence characteristics at the entrainment threshold of sediment beds. J Hydraul Eng 137(9):945-958

Duan JG, He L, Fu X, Wang Q (2009) Mean flow and turbulence around experimental spur dike. Adv Water Resour 32(12):1717-1725

Duan J, He L, Wang G, Fu X (2011) Turbulent burst around experimental spur dike. Int J Sedim Res 26(4):471-523

Elder J (1959) The dispersion of marked fluid in turbulent shear flow. J Fluid Mech 5(04):544-560

Erpicum S, Nagel V, Laugier F (2011) Piano key weir design study at Raviege dam.In: Labyrinth and Piano Key Weirs-PKW 2011

Fan J, Morris GL (1992) Reservoir sedimentation. I: delta and density current deposits. J Hydraul Eng 118(3):354-369

Finelli CM, Hart DD, Fonseca DM (1999) Evaluating the spatial resolution of an acoustic Doppler velocimeter and the consequences for measuring near-bed flows. Limnol Oceanogr 44(7):1793-1801

Gad-el-Hak M (1989) Flow control. Appl Mech Rev 42(10):261-293

García CM, Cantero MI, Niño Y, García MH (2007) Discussions and closures. J Hydraul Eng:1283

Graham E, Harvey R, Barton N, Mills C (2013) Issues and Challenges with Wet-Gas Sampling. Meas Control 46(2):58-62

Grahn H, Szeverenyi NM, Roggenbuck MW, Delaglio F, Geladi P (1989) Data analysis of multivariate magnetic resonance images I. A principal component analysis approach. Chemom Intell Lab Syst 5(4):311-322

Grass A (1971) Structural features of turbulent flow over smooth and rough boundaries. J Fluid Mech 50(02):233-255

Guellouz M, Tavoularis S (2000) The structure of turbulent flow in a rectangular channel containing a cylindrical rod-Part 1: reynolds-averaged measurements. Exp Thermal Fluid Sci 23(1):59-73

Gurley K, Kareem A (1999) Applications of wavelet transforms in earthquake, wind and ocean engineering. Eng Struct 21(2):149-167

Gurley K, Kijewski T, Kareem A (2003) First-and higher-order correlation detection using wavelet transforms. J Eng Mech 129(2):188-201

Hino M, Kashiwayanagi M, Nakayama A, Hara T (1983) Experiments on the turbulence statistics and the structure of a reciprocating oscillatory flow. J Fluid Mech 131:363-400

Hoyas S, Jiménez J (2006) Scaling of the velocity fluctuations in turbulent channels up to $\operatorname{Re} \tau=2003$. Phys Fluids (1994present) 18(1):011702

Hutchins N, Nickels TB, Marusic I, Chong M (2009) Hot-wire spatial resolution issues in wall-bounded turbulence. J Fluid Mech 635:103-136

Jones W, Whitelaw J (1982) Calculation methods for reacting turbulent flows: a review. Combust Flame 48:1-26

Kabiri-Samani A, Javaheri A (2012) Discharge coefficients for free and submerged flow over Piano Key weirs. J Hydraul Res 50(1):114-120

Keylock CJ, Singh A, Venditti JG, Foufoula-Georgiou E (2014) Robust classification for the joint velocity-intermittency structure of turbulent flow over fixed and mobile bedforms. Earth Surface Process Landf 39:1717-1728

Kim J, Moin P, Moser R (1987) Turbulence statistics in fully developed channel flow at low Reynolds number. J Fluid Mech 177:133-166
Kim S, Im J, Lee SO (2014) Assessment of sediment exclusion efficiency for several modified Labyrinth weirs. Paddy Water Environ 1-8

Kondolf GM, Gao Y, Annandale GW, Morris GL, Jiang E, Zhang J, Cao Y, Carling P, Fu K, Guo Q (2014) Sustainable sediment management in reservoirs and regulated rivers: experiences from five continents. Earth's Future 2:256-280

Kovasznay LS (2012) The hot-wire anemometer in supersonic flow. J Aeronaut Sci 17(9)

Krogstadt P-Å, Antonia R (1999) Surface roughness effects in turbulent boundary layers. Exp Fluids 27(5):450-460

Kumar P, Foufoula-Georgiou E (1997) Wavelet analysis for geophysical applications. Rev Geophys 35(4):385-412

Laugier F, Vermeulen J, Pralong J (2012) Achievement of New Innovative Labyrinth Piano Key Weir Spillways (PKW). In: Proceedings of piano key weir for in-stream storage and dam safety (pKwIsD-2012), New Delhi. New Delhi, India, pp 25-42

Lavoie P, Avallone G, De Gregorio F, Romano G, Antonia R (2007) Spatial resolution of PIV for the measurement of turbulence. Exp Fluids 43(1):39-51

Lee J, Suh J, Sung HJ, Pettersen B (2012) Structures of turbulent open-channel flow in the presence of an air-water interface. J Turbul (13)

Lien R-C, D'Asaro EA (2006) Measurement of turbulent kinetic energy dissipation rate with a Lagrangian float. J Atmos Ocean Technol 23(7):964-976

Lim S-Y (1997) Equilibrium clear-water scour around an abutment. J Hydraul Eng 123(3):237-243

Liu C, Shen Y-M (2008) Flow structure and sediment transport with impacts of aquatic vegetation. J Hydrodyn Ser B 20(4):461-468

Liu C, Huang J-B, Zhu Z, Jiang F, Tung S, Tai Y-C, Ho C-M (1999) A micromachined flow shear-stress sensor based on thermal transfer principles. Microelectromechanical Syst J 8(1):90-99

Liu M, Rajaratnam N, Zhu DZ (2004) Turbulence structure of hydraulic jumps of low Froude numbers. J Hydraul Eng 130(6):511-520

Mazumder B, Sarkar K (2014) Turbulent flow characteristics and drag over 2-D forward-facing dune shaped structures with two different stoss-side slopes. Environ Fluid Mech 14(3):617-645

McComb WD (1990) The physics of fluid turbulence. Chem Phys 1

Mujica LE, Vehi J, Ruiz M, Verleysen M, Staszewski W, Worden K (2008) Multivariate statistics process control for dimensionality reduction in structural assessment. Mech Syst Signal Process 22(1):155-171

Nagata N, Hosoda T, Nakato T, Muramoto Y (2005) Threedimensional numerical model for flow and bed deformation around river hydraulic structures. J Hydraul Eng 131(12):1074-1087

Nakagawa H, Nezu I (1977) Prediction of the contributions to the Reynolds stress from bursting events in open-channel flows. J Fluid Mech 80(01):99-128

Nakagawa H, Nezu I (1981) Structure of space-time correlations of bursting phenomena in an open-channel flow. J Fluid Mech 104:1-43

Nakagawa H, Nezu I (1987) Experimental investigation on turbulent structure of backward-facing step flow in an open channel. J Hydraul Res 25(1):67-88

Nakra B, Chaudhry K (2004) Instrumentation, measurement and analysis. Tata McGraw-Hill Education, New York

Nayan Sharma GS (2007) The Piano Key Weir: a New Dam Safety Solution for Enhanced Spillway Capacity. Proc Ann Conf Assoc State Dam Safety Off:113-128

Nayan Sharma HT (2013) Experimental study on vertical velocity and submergence depth near piano key weir. Labyrinth Piano Key Weirs II:93-100

Nezu, I. (1993). "Turbulence in open-channel flows." 
Nezu I (2005) Open-channel flow turbulence and its research prospect in the 21st century. J Hydraul Eng 131(4):229-246

Nezu I, Rodi W (1986) Open-channel flow measurements with a laser Doppler anemometer. J Hydraul Eng 112(5):335-355

Nezu I, Sanjou M (2011) PIV and PTV measurements in hydrosciences with focus on turbulent open-channel flows. J Hydro Environ Res 5(4):215-230

Nikora VI, Goring DG (1998) ADV measurements of turbulence: can we improve their interpretation? J Hydraul Eng 124(6):630-634

Oh D-S, Lee C-H (2011) A comparative study of flow rate characteristics of an averaging Pitot tube type flow meter according to $\mathrm{H}$ parameters based on two kinds of differential pressure measured at the flow meter with varying air temperature. J Mech Sci Technol 25(8):1961-1967

Ouamane A (2013) Improvement of labyrinth weirs shape. In: Proc., Labyrinth and Piano Key Weirs II-PKW 2013. CRC Press, Taylor \& Francis Group, London

Payne JT, Wood AW, Hamlet AF, Palmer RN, Lettenmaier DP (2004) Mitigating the effects of climate change on the water resources of the Columbia River basin. Clim Change 62(1-3):233-256

Penney C (1969) Differential Doppler velocity measurements. Quantum Electron IEEE J 5(6):318

Poggi D, Porporato A, Ridolfi L (2003) Analysis of the small-scale structure of turbulence on smooth and rough walls. Phys Fluids 15(1):35

Raupach M (1981) Conditional statistics of Reynolds stress in roughwall and smooth-wall turbulent boundary layers. J Fluid Mech 108:363-382

Raupach M, Thom AS (1981) Turbulence in and above plant canopies. Ann Rev Fluid Mech 13(1):97-129

Raupach M, Antonia R, Rajagopalan S (1991) Rough-wall turbulent boundary layers. Appl Mech Rev 44(1):1-25

Raupach M, Finnigan J, Brunei Y (1996) Coherent eddies and turbulence in vegetation canopies: the mixing-layer analogy. Bound-Layer Meteorol 78(3-4):351-382

Reeks MW (2014) Transport, mixing and agglomeration of particles in turbulent flows. Flow Turbul Combust 92(1-2):3-25

Rhoads B, Massey K (2012) Flow structure and channel change in a sinuous grass-lined stream within an agricultural drainage ditch: implications for ditch stability and aquatic habitat. River Res Appl 28(1):39-52

Roy AG, Buffin-Belanger T, Lamarre H, Kirkbride AD (2004) Size, shape and dynamics of large-scale turbulent flow structures in a gravel-bed river. J Fluid Mech 500:1-27

Salazar JP, Collins LR (2012) Inertial particle relative velocity statistics in homogeneous isotropic turbulence. J Fluid Mech 696(305):45
Sharma N, Tiwari H, Singhal GD (2012) Piano-key weir technology: a possible solution of Dam safety in narrow river and existing dams. In: Proc. Dams and Spillways in Himalayan Regions, Water Resources Department, BIS. India, pp 118-123

Shvidchenko AB, Pender G (2001) Macroturbulent structure of openchannel flow over gravel beds. Water Resour Res 37(3):709-719

Simpson RL (1996) Aspects of turbulent boundary-layer separation. Prog Aerosp Sci 32(5):457-521

Simpson RL (2001) Junction flows. Ann Rev Fluid Mech 33(1):415-443

Smits A, Hayakawa K, Muck K (1983) Constant temperature hot-wire anemometer practice in supersonic flows. Exp Fluids 1(2):83-92

Song T, Chiew Y (2001) Turbulence measurement in nonuniform open-channel flow using acoustic Doppler velocimeter (ADV). J Eng Mech 127(3):219-232

Speziale CG (1990) Analytical methods for the development of Reynolds stress closures in turbulence. DTIC Document

Sukhodolov A, Thiele M, Bungartz H (1998) Turbulence structure in a river reach with sand bed. Water Resour Res 34(5):1317-1334

Tachie M, Bergstrom D, Balachandar R (2000) Rough wall turbulent boundary layers in shallow open channel flow. J Fluids Eng 122(3):533-541

Taylor G (1954) The dispersion of matter in turbulent flow through a pipe. Proc R Soc Lond A 223(1155):446-468

Tiwari H, Sharma N (2014) Gaps and scope of turbulence study near piano key weir (PKW). In: H. L. Tiwari, S. Suresh, and R. K. Jaiswal, (eds) Hydraulics, water resources, coastal and environmental engineering. Excellent Publishing House, Maulana Azad National Institute of Technology Bhopal. pp 486-492

Tominaga A, Nezu I (1991) Turbulent structure in compound openchannel flows. J Hydraul Eng 117(1):21-41

Vom Stein HD, Pfeifer HJ (1969) A Doppler difference method for velocity measurements. Metrologia 5(2):59

Voulgaris G, Trowbridge JH (1998) Evaluation of the acoustic Doppler velocimeter (ADV) for turbulence measurements. J Atmos Ocean Technol 15(1):272

Wang S, Cui J (2005) Sensor-fault detection, diagnosis and estimation for centrifugal chiller systems using principal-component analysis method. Appl Energy 82(3):197-213

Wang X, Yang Q, Lu W, Wang X (2012) Experimental study of nearwall turbulent characteristics in an open-channel with gravel bed using an acoustic Doppler velocimeter. Exp Fluids 52(1):85-94

Yeh Y, Cummins H (1964) Localized fluid flow measurements with an $\mathrm{He}-\mathrm{Ne}$ laser spectrometer. Appl Phys Lett 4(10):176-178 